\title{
Aggregatibacter aphrophilus
}

National Cancer Institute

\section{Source}

National Cancer Institute. Aggregatibacter aphrophilus. NCI Thesaurus. Code C86134.

A species of facultatively anaerobic, Gram negative, rod shaped bacteria assigned to the phylum Proteobacteria. This bacteria is catalase and urease negative, oxidase variable, does not require $X$ factor and acid is produced from glucose, fructose and mannose. A. aphrophilus is found in human oral flora, oropharyngeal flora and dental plaque, and is a cause of infectious endocarditis. 